\title{
The Effectiveness of Three Irrigation Systems in the Enterococcus faecalis Reduction after Instrumentation with a Reciprocating Instrument
}

\author{
Karina Gonzalez Camara Fernandes ${ }^{1}$ Bruno Barciela da Silva ${ }^{1}$ Nilton César Boer ${ }^{1}$ \\ Danilo Rodrigues Mandarini ${ }^{1}$ Lucieni Cristina Trovati Moreti ${ }^{1}$ Augusto Shoji Kato ${ }^{2}$ \\ Carlos Eduardo da Silveira Bueno ${ }^{2}$ Ana Grasiela da Silva Limoeiro ${ }^{3}$ Sergio Luiz Pinheiro 4 \\ Alexandre Sigrist De Martin ${ }^{2}$ Carlos Eduardo Fontana ${ }^{4}$
}

1Department of Endodontics, College of Dentistry, Universidade
Brasil, Fernandópolis, São Paulo, Brazil
2Department of Endodontics, College of Dentistry, Faculdade São
Leopoldo Mandic, Instituto de Pesquisas São Leopoldo Mandic,
Campinas, SP, Brazil
3Department of Endodontics, College of Dentistry, Faculdade de
Ilhéus Bahia, Ilhéus, Bahia, Brazil
4Department of Endodontics, Postgraduate Program in Health
Sciences, Pontifical Catholic University of Campinas (PUC- Campinas),
Postgraduate Program in Health Sciences, Campinas, São Paulo, Brazil

Address for correspondence Ana Grasiela Limoeiro, Rua Castro Alves, 100, Caixa Postal 05, Centro Iguaí- BA 45.280.000, Brazil (e-mail: grasielalimoeiro@gmail.com).

Eur J Dent:2020;14:539-543

\begin{abstract}
Keywords

- endodontics

- EndoActivator

- Easy Clean

- Enterococcus faecalis

- PUI

Objective This study aimed to analyze the effectiveness of three irrigation systems: EndoActivator, passive ultrasonic irrigation (PUI), and Easy Clean in the reduction of Enterococcus faecalis, after instrumentation with the reciprocating system, through microbiological collection and culture method.

Materials and Methods A total of 60 extracted human lower premolars were used and standardized at $16 \mathrm{~mm}$ in length. The teeth were accessed, contaminated with E. faecalis, and incubated for 21 days at $37^{\circ} \mathrm{C}$. Initial collections (S1) were made with an absorbent paper cone to confirm the contamination; subsequently, instrumentation was performed with WaveOne Primary. The teeth were divided into four groups according to the final irrigation protocol $(n=15)$ : group 1. EndoActivator; group 2, PUI; group 3, Easy Clean; and group 4, control group irrigated with saline solution sterile and without agitation. In the final irrigation, the agitation of the $17 \%$ ethylene amine tetra-acetic acid (EDTA) solutions was used, then $2.5 \%$ sodium hypochlorite $(\mathrm{NaOCl})$; in both for this, three cycles of 20 seconds each. After the chemicalmechanical preparation and agitation of the irrigating solutions, the final collections (S2) for counting the colony-forming units (CFU/mL) occurred.

Results The Kruskal-Wallis test revealed that all the agitation systems reduced by $100 \%$ and the control group by $65.7 \%$.

Conclusion The control group presented a significantly higher amount of CFU/mL after the chemical-mechanical preparation than the other groups, which were similar to each other $(p>0.05)$.
\end{abstract}

\section{Introduction}

The success of endodontic treatment depends on the eradication of microorganisms present in the root canal system and the prevention of reinfection. Therefore, it needs to be modeled with manual or automated instruments under constant irrigation, to remove inflamed or necrotic tissue, microorganisms, and other debris. Endodontic treatment aims to promote proper cleaning and disinfection of the root canal 
system, ${ }^{1}$ in addition to facilitating irrigation, disinfection, and filling. ${ }^{2}$ The instrumentation is effective in disorganizing the bacterial biofilm and reducing the presence of microorganisms in the main root canal. ${ }^{3-5}$ However, it is necessary for the aid of the irrigation through chemical substances to potentiate the cleaning and disinfection of the canal system. Enterococcus faecalis is one of the most common species found in persistent root canal infections. ${ }^{6}$

Many different irrigation protocols have been used in endodontics to optimize the disinfection of the root canal. ${ }^{7-10}$ Irrigation with activation using ultrasonic tips is a muchcited technique in the current literature. Passive ultrasonic irrigation (PUI) with the Irrisonic E1 tip (Helse; Santa Rosa do Viterbo, São Paulo, Brasil) was tested in this study. The energy released by the instrument increases the properties of the irrigating solution, ${ }^{11}$ from the creation of two physical phenomena, microacoustic current formation and cavitation. ${ }^{12}$ The sonic device EndoActivator (EA; Dentsply Tulsa Dental, Tulsa, OK, EUA) consists of a sonic generator, which performs agitation of the irrigating solution creating a hydrodynamic phenomenon obtained through systems that operate at low frequency ( 1 to $6 \mathrm{kHz}$ ) and high range of motion, promoting a more uniform circulation of the irrigant. Its use is recommended after completion of the chemical-mechanical preparation for the activation of ethylene amine tetra-acetic acid (EDTA) and sodium hypochlorite $(\mathrm{NaOCl})$. It has three flexible polymer-based tips in three diameters and different tapers, without cutting power, in sizes: 15/02 yellow, 25/04 red, and 35/04 blue and can be activated in three speeds: 2,000, 6,000 , and 10,000 cycles per minute $(\mathrm{cpm}) \cdot{ }^{13}$ Easy Clean (EC; Easy Equipamentos Odontológicos, Belo Horizonte, Brasil) is an acrylonitrile butadiene styrene (ABS) polymer size 25.04 instrument, whose cross-section resembles the "airplane wing" and operates in the reciprocating motion, clockwise and counterclockwise, promoting constant agitation of the chemical irrigating substance. ${ }^{14}$ This study aimed to analyze the effectiveness of three irrigation systems: EA, PUI with the Irrisonic E1 tip, and EC in the reduction of E. faecalis, after instrumentation with the reciprocating system, through microbiological collection and culture method.

\section{Materials and Methods}

The research was approved by the Research Ethics Committee of the São Leopoldo Mandic Dental Research Center of Campinas/SP, under the number 1,563.716 and performed at the laboratory of microbiology of said institution. Sixty unirradicular permanent human premolars were used, extracted for orthodontic or periodontal reasons. The sample number for each experimental group $(n=15)$ was determined from the analysis of publications with similar methodologies. ${ }^{15,16}$

The inclusion criteria were teeth with complete rhizogenesis, without curvature, that did not undergo endodontic treatment, without calcification and apical diameter compatible with a K \#15 file (Dentsply/Maillefer, Ballagigues, Switzerland). The teeth were standardized at $16 \mathrm{~mm}$ by cutting the coronary portion with carborundum disc, and the working length (WL) was determined at $15 \mathrm{~mm}$. Canal exploration and apical patency occurred with $\mathrm{K} \# 10$ file, and canals were instrumented by manual technique progressively up to $\mathrm{K} \# 20$ file. At each instrument change, the canal was irrigated with $1 \mathrm{~mL}$ of $2.5 \% \mathrm{NaOCl}$.

The apical foramina of each root canal were sealed with photopolymerizable composite resin. The external waterproofing of the roots, except for the cervical region at the entrance of the root canal, was performed with two layers of Araldite epoxy adhesive. After the waterproofing, the specimens were wrapped with Optosil/Xantopren condensing silicone and then autoclaved at $121^{\circ} \mathrm{C}$ for 15 minutes. The canals were contaminated with pure cultures of the standard E. faecalis strain obtained from the American Type Culture Collection (ATCC 29212). For the reactivation of the strains, cultures were transferred using a bacteriological loop, to brain and heart infusion (BHI) broth and incubated in an incubator at $37^{\circ} \mathrm{C}$ for 24 hours, with $5 \%$ carbon dioxide $\left(\mathrm{CO}_{2}\right)$. After microbial growth, tube suspension was prepared to contain $10 \mathrm{~mL}$ of sterile physiological solution, compatible with the McFarland scale 10.0 turbidity standard. In a sterile test tube, $5 \mathrm{~mL}$ of the suspension prepared was mixed with $5 \mathrm{~mL}$ of BHI broth to obtain the final concentration suspension.

The final concentration with $20 \mu \mathrm{L}$ of $E$. faecalis suspension was placed into the root canals of the specimens with the aid of an insulin syringe and after each root canal entry, a sterile cotton ball embedded in the suspension. In four wells of each cell culture dish, sterile cotton, moistened with sterile distilled water, was introduced to ensure the humidity of the environment. The lid of the plate was closed and sealed with adhesive tape and the assembly incubated in a $\mathrm{CO}_{2}$ oven at $37^{\circ} \mathrm{C}$ for 21 days. BHI broth of $20 \mu \mathrm{L}$ was added to the root canals every 2 days with the aid of a $0.3 \mathrm{cc}$ insulin syringe and the cotton soaked in distilled water was exchanged in the wells of the plates. ${ }^{17}$

Confirmation of the viability and purity of the microorganisms within the canal system occurred weekly using random collection in two teeth with the aid of a sterilized no. 20 absorbent paper cone held inside the canal for 1 minute, seeded in BHI broth and incubated in an oven at $37^{\circ} \mathrm{C}$ with $5 \%$ $\mathrm{CO}_{2}$ for 24 hours. After 21 days of contamination, a cone of sterilized no. 20 absorbent paper was inserted into the root canal of each specimen for one minute and then transferred with the aid of a sterilized forceps to a polypropylene flap with $1 \mathrm{~mL}$ of physiological sterilized solution $(0.9 \% \mathrm{NaCl})$. It was stirred for 30 seconds on a tube shaker. From this suspension, serial dilutions up to 10 were handled. Aliquots of $0.1 \mathrm{~mL}$ of the suspension and each dilution were seeded into Petri dishes containing BHI agar. These were incubated in an oven at $37^{\circ} \mathrm{C}$ for 24 hours. Subsequently, the number of colony-forming units (CFUs) per plate was counted, and the number of $\mathrm{CFU} / \mathrm{mL}^{18}$ was calculated.

\section{Group 1: EasyClean $n=15$.}

The EA tip 25.04 was used at $2 \mathrm{~mm}$ from the working length (Ruddle, 2008).

Group 2: PUI $n=15$ 
The tip E1 Irrisonic 20/0.01, fitted to an ultrasound, $1 \mathrm{~mm}$ from the WL.

\section{Group 3: EC $n=15$}

EC (25.04) was introduced into the WL in the reciprocating motion. For this, the X-Smart Plus engine was used in Wavene mode.

\section{Group 4: Control (C) $n=15$}

The Navitip irrigation needle was coupled to a plastic syringe with $2.5 \mathrm{~mL}$ of sterile saline solution and introduced into the canal without agitation of the irrigation solution.

\section{All Groups}

The teeth were instrumented with the WaveOne Primary system (Dentsply; Maillefer, Balaigues, Switzerland) with the X-Smart Plus electric motor. The irrigation of the canals occurred with the aid of a plastic syringe and Navitip needle, using a total of $20 \mathrm{~mL} \mathrm{NaOCl} 2.5 \%$. After the instrumentation of the canals, the agitation protocol was three cycles of 20 second of sodium hypochlorite, three cycles of EDTA, and three cycles of hypochlorite according to each system. After completion of instrumentation and final irrigation, $10 \%$ sodium thiosulfate was used to neutralize $\mathrm{NaOCl}$ before microbiological collection. Sample collection of the root canal contents was done with a sterile no. 25 absorbent paper cone, diluted and seeded in Petri dish containing BHI agar, to verify bacterial growth. After 1 minute in the canal, the cone was transferred to a polypropylene flap containing $1 \mathrm{~mL}$ of sterile physiological solution ( $\mathrm{NaCl} 0.9 \%$ ), shaken for 30 seconds on a tube shaker. From this suspension, dilutions up to 10 were prepared. Aliquots of $0.1 \mathrm{~mL}$ of the suspension and each dilution were seeded into Petri dishes containing BHI agar. These were incubated in a greenhouse with $5 \% \mathrm{CO}_{2}$ at $37^{\circ} \mathrm{C}$ for 24 hours. Subsequently, the CFU number was counted per plate, using the colony counter, calculating the number of $\mathrm{CFU} / \mathrm{mL}$.

\section{Results}

The Kruskal-Wallis test, applied to both dilutions, revealed significant differences between groups $(p<0.01)$. Dunn's multiple comparison tests showed that the control group had a significantly higher amount of $\mathrm{CFU} / \mathrm{mL}$ after the chemical-mechanical preparation than the other groups, similar to each other $(p>0.05$ ( - Tables 1 and $\mathbf{2}$ ). The results of the Wilcoxon's test, applied to the intragroup data for both dilutions (reduction in the number of $\mathrm{CFU} / \mathrm{mL}$ ), are shown in - Table 3 . The results showed that all groups significantly reduced the number of bacteria in the root canals, except for the control group. The results showed that all groups significantly reduced the number of bacteria in the root canals, except for the control group ( - Fig. 1).

Table 3 Results of the Wilcoxon's test for intragroup data

\begin{tabular}{|l|l|l|}
\hline & Dilution $1 \times 10^{-1}$ & Dilution $1 \times 10^{-2}$ \\
\hline EndoActivator & $p=0.0005$ & $p=0.0020$ \\
\hline PUI & $p=0.0010$ & $p=0.0039$ \\
\hline EasyClean & $p=0.0001$ & $p=0.0010$ \\
\hline Control & $p=0.3575$ & $p=0.0857$ \\
\hline
\end{tabular}

Abbreviation: PUI, passive ultrasonic irrigation.

Table 1 CFU/mL count of Enterococcus faecalis before and after chemical-mechanical preparation with three different irrigation systems, for $1 \times 10$ dilution

\begin{tabular}{|l|l|l|l|l|l|l|l|}
\hline \multirow{2}{*}{} & \multicolumn{3}{|c|}{ S1 } & \multicolumn{3}{c|}{ S2 } & $\begin{array}{c}\text { \% of reduction } \\
\text { S1 for S2 }\end{array}$ \\
\cline { 2 - 8 } & Average & Median & Amplitude & Average & Median & Amplitude & Average (Amplitude) \\
\hline EndoActivator & $4,0 \times 10^{6}$ & $7,1 \times 10^{4}$ & 0 a $1 \times 10^{7}$ & $8,6 \times 10^{1}(\mathrm{~A})$ & 0,0 & 0 a $1,2 \times 10^{3}$ & $97,2(66,7$ a 100,0$)$ \\
\hline PUI & $3,4 \times 10^{6}$ & $1,8 \times 10^{4}$ & 0 a $1 \times 10^{7}$ & $2,7 \times 10^{1}(\mathrm{~A})$ & 0,0 & 0 a $4,0 \times 10^{2}$ & $100(-)$ \\
\hline EasyClean & $4,0 \times 10^{6}$ & $2,0 \times 10^{4}$ & 0 a $1 \times 10^{7}$ & $0,0(\mathrm{~A})$ & 0,0 & - & $100(-)$ \\
\hline Control & $4,0 \times 10^{6}$ & $6,0 \times 10^{4}$ & 0 a $1 \times 10^{7}$ & $2,0 \times 10^{6}(\mathrm{~B})$ & $2,0 \times 10^{4}$ & 0 a $1,0 \times 10^{7}$ & $47,5(0,0$ a 100,0$)$ \\
\hline
\end{tabular}

Abbreviations: CFU, colony-forming unit; PUI, passive ultrasonic irrigation.

Note: different letters indicate statistically significant differences between groups $(\alpha=0.05)$.

Table 2 CFU/mL count of Enterococcus faecalis before and after chemical-mechanical preparation with three different irrigation systems, for $1 \times 10$ dilution

\begin{tabular}{|l|l|l|l|l|l|l|l|}
\hline \multirow{2}{*}{} & \multicolumn{3}{|c|}{} & \multicolumn{2}{c|}{ S2 } & $\begin{array}{c}\text { \% of reduction } \\
\text { S1 for S2 }\end{array}$ \\
\cline { 2 - 8 } & Average & Median & Amplitude & Average & Median & Amplitude & $\begin{array}{l}\text { Average } \\
\text { (Amplitude) }\end{array}$ \\
\hline EndoActivator & $3,4 \times 10^{6}$ & $4,8 \times 10^{4}$ & 0 a $1 \times 10^{7}$ & $0,0(\mathrm{~A})$ & 0,0 & - & $100(-)$ \\
\hline PUI & $2,9 \times 10^{6}$ & $3,6 \times 10^{4}$ & 0 a $1 \times 10^{7}$ & $0,0(\mathrm{~A})$ & 0,0 & - & $100(-)$ \\
\hline EasyClean & $8,0 \times 10^{5}$ & $1,3 \times 10^{4}$ & $0 \mathrm{a} 1 \times 10^{7}$ & $0,0(\mathrm{~A})$ & 0,0 & - & $100(-)$ \\
\hline Control & $2,7 \times 10^{6}$ & $9,2 \times 10^{4}$ & $0 \mathrm{a} 1 \times 10^{7}$ & $4,8 \times 10^{4}(\mathrm{~B})$ & $2,8 \times 10^{4}$ & $0 \mathrm{a} 1,9 \times 10^{5}$ & $65,7(0,0 \mathrm{a} 100,0)$ \\
\hline
\end{tabular}

Note: different letters indicate statistically significant differences between groups $(\alpha=0.05)$. 


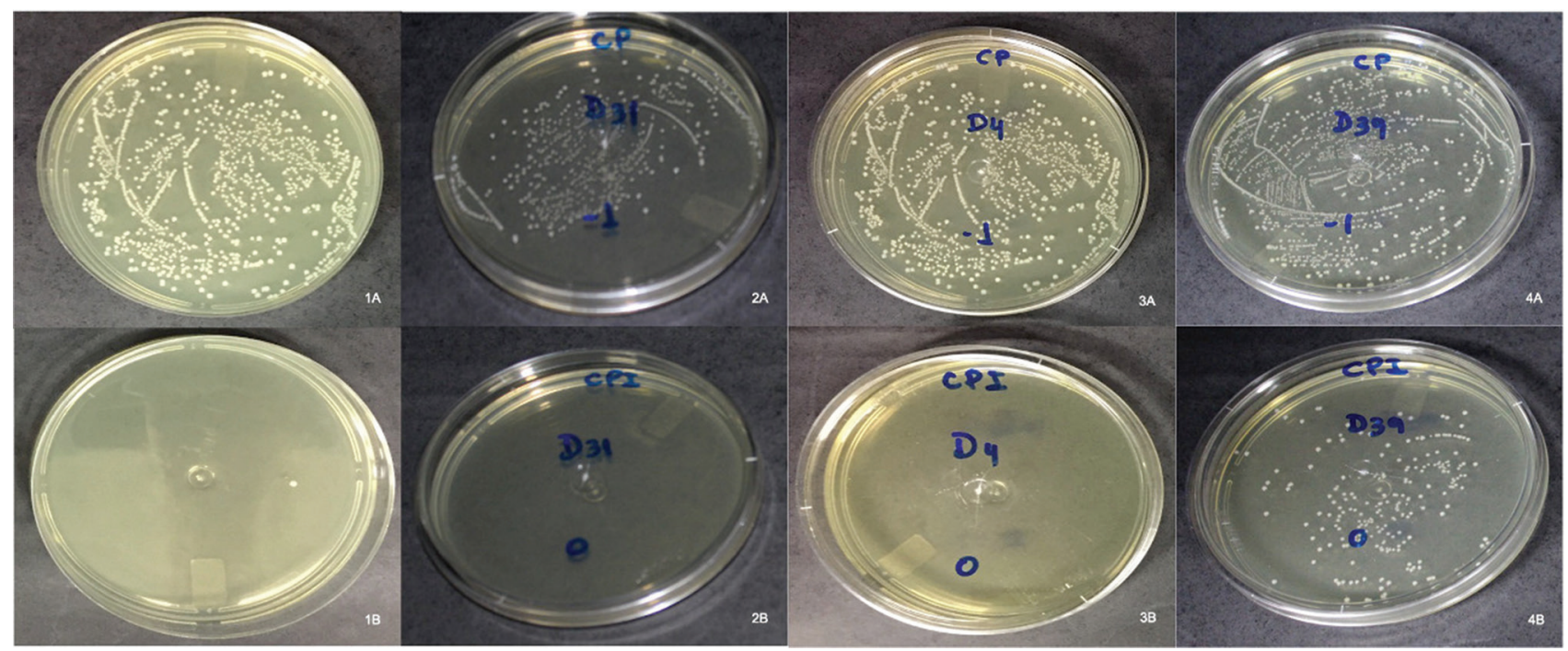

Fig. 1 1(A), 2(A), 3(A), and 4(A) images prior to irrigation and instrumentation of PUI, Easy Clean, EndoActivator, and control group respectively. 1(B), 2(B), 3(B), and 4(B) postinstrumentation images of PUI, Easy Clean, EndoActivator and control group respectively. PUI, passive ultrasonic irrigation.

\section{Discussion}

The purpose of endodontic treatment is to remove the cause of the inflammatory/infectious process of the root canal system to recover and maintain the health of the periapical tissues. Mechanical removal by instrumentation is particularly useful in disrupting bacterial biofilm. It reduces the presence of bacteria in the main root canal, ${ }^{19}$ but penetration of the irrigant into anatomically complex areas inaccessible to the instruments plays a decisive role in the control of microorganisms. ${ }^{20}$ The association of agitation systems with chemical irrigation solutions more effectively reduces the microbial load of the canal system. ${ }^{21}$

E. faecalis was chosen as a bacteriological marker because it is one of the bacterial species most frequently found in persistent infections of the root canals, ${ }^{22}$ presenting a high capacity to penetrate the interior of the dentinal tubules. Besides, the pathogenicity of the bacteria is also influenced by environmental factors, such as high bacterial load, interactions between different species, causing collective pathogenicity, host resistance, changes in the virulence factors regulated by the environment, and resistance of the host when in contact with the periapical tissues and defense cells. ${ }^{23}$

The teeth used in this study were previously autoclaved at $121^{\circ} \mathrm{C}$ for 20 minutes, according to recent research methodology. ${ }^{17,18}$ With autoclave sterilization, changes occur in dentin components, such as collagen, ${ }^{24}$ causing less bacterial adhesion when compared with fresh nonsterile or gamma-sterilized dentin. The microbiological collection of root canals does not allow to measure the depth of bacterial invasion in the dentinal tubules. Caution should be exercised when comparing the results of other studies or even among the specimens used in the same study due to the impossibility of standardization concerning dentin properties. The intratubular penetration of bacteria depends on the composition and architecture of the dentinal tubules and can be reduced in the apical third or elderly individuals with more regions of sclerotic dentine. ${ }^{25}$ Preinstrumentation collection revealed quantitative differences in bacterial growth between the initial samples, although not statistically significant. One possible reason for this may be the impossibility of standardizing specimens to the age of donors. In older individuals, the formed biofilm may be less stable due to the higher deposition of mineralized dentinal tissue. ${ }^{26}$ The paper cone may not absorb bacteria present in apical branches or dentin tubules during collection and, therefore, this technique may fail to detect viable bacteria generating false results. ${ }^{27}$

The PUI consists, after completing the root canal instrumentation, to position an instrument of small diameter at its center and closest to the apical region, so that the instrument acts passively, agitating the irrigator so that it quickly penetrates the apical third. The instrument should remain free within the root canal without touching its walls. ${ }^{28}$

The EC system acts through a reciprocating or rotating mechanical movement, and as a plastic file can be introduced to the WL. In the present study, EC worked on WL, PUI at $1 \mathrm{~mm}$ below and EA at $2 \mathrm{~mm}$ from the WL. Duque et al ${ }^{29}$ compared the efficacy of EA, EC, and PUI for the removal of isthmus debris from mesial roots of lower molars by scanning electron microscopy and concluded that rotational EC promoted better cleaning of the canal and isthmus. The positive results with the use of the EC device can be explained by the fact that it has been used in the rotational movement and its blades act on the walls of the root canals, releasing debris and microorganisms, as shown by the study by Simezo et al $^{30}$ Huffaker et $\mathrm{al}^{31}$ compared the EA and the conventional syringe irrigation system to evaluate the microbial reduction in root canals associated with the use of intracanal medication with calcium hydroxide. There was no significant difference between the groups. In both the sonic and the ultrasonic systems, there is acoustic cavitation, which can be defined as the creation of bubbles. When associated with $\mathrm{NaOCl}$, it results in a more significant number of small bubbles, and, activating three cycles of 20 seconds, promotes a 
more efficient cleaning, removing debris from dentin, microorganisms, and organic matter. ${ }^{32}$ Andrade et $\mathrm{a}^{33}$ compared $\mathrm{PUI}, \mathrm{EC}$ in the reciprocating motion, EC in rotational movement and control group without activation and the results revealed that EC in rotational movement and PUI, surpassed EC in the reciprocating movement. This result was different from that of Kato et a ${ }^{14}$ who demonstrated that EC in reciprocating movement presented better performance than PUI in the apical third. The sonic system presented similar performance to the ultrasonic and to the EC system, regarding the removal of microorganisms, this may have happened due to the use of teeth with straight roots.

\section{Conclusion}

It was concluded that the EC, PUI, and EA systems showed a microbial reduction in root canals contaminated with E. faecalis, different from the control group.

\section{Conflict of Interest}

None declared.

\section{References}

1 Chivatxaranukul P, Dashper SG, Messer HH. Dentinal tubule invasion and adherence by Enterococcus faecalis. Int Endod J 2008;41(10):873-882

2 Haapasalo M, Shen Y, Qian W, Gao Y. Irrigation in endodontics. Dent Clin North Am 2010;54(2):291-312

3 Machado ME, Sapia LA, Cai S, Martins GH, Nabeshima CK. Comparison of two rotary systems in root canal preparation regarding disinfection. J Endod 2010;36(7):1238-1240

4 Martinho FC, de Rabello DG, Ferreira LL, Nascimento GG. Participation of endotoxin in root canal infections: A systematic review and meta-analysis. Eur J Dent 2017;11(3):398-406

5 Dubey S, Saha SG, Rajkumar B, Dhole TK. Comparative antimicrobial efficacy of selected root canal irrigants on commonly isolated microorganisms in endodontic infection. Eur J Dent 2017;11(1):12-16

6 Gomes BP, Pinheiro ET, Jacinto RC, Zaia AA, Ferraz CC, SouzaFilho FJ. Microbial analysis of canals of root-filled teeth with periapical lesions using polymerase chain reaction. J Endod 2008;34(5):537-540

7 Gu LS, Kim JR, Ling J, Choi KK, Pashley DH, Tay FR. Review of contemporary irrigant agitation techniques and devices. J Endod 2009;35(6):791-804

8 Dioguardi M, Gioia GD, Illuzzi G, Laneve E, Cocco A, Troiano G. Endodontic irrigants: Different methods to improve efficacy and related problems. Eur J Dent 2018;12(3):459-466

9 Podar R, Kulkarni GP, Dadu SS, Singh S, Singh SH. In vivo antimicrobial efficacy of $6 \%$ Morinda citrifolia, Azadirachta indica, and 3\% sodium hypochlorite as root canal irrigants. Eur J Dent 2015;9(4):529-534

10 Pinheiro SL, Silva CC, Silva LAD, et al. Antimicrobial efficacy of $2.5 \%$ sodium hypochlorite, $2 \%$ chlorhexidine, and ozonated water as irrigants in mesiobuccal root canals with severe curvature of mandibular molars. Eur J Dent 2018;12(1):94-99

11 Roy RA, Ahmad M, Crum LA. Physical mechanisms governing the hydrodynamic response of an oscillating ultrasonic file. Int Endod J 1994;27(4):197-207

12 Al-Jadaa A, Paqué F, Attin T, Zehnder M. Acoustic hypochlorite activation in simulated curved canals. J Endod 2009;35(10):1408-1411

13 Ruddle C. Endodontic disinfection - tsunami irrigation. Saudi Endod J 2015;5:1-12

14 Kato AS, Cunha RS, da Silveira Bueno CE, Pelegrine RA, Fontana $\mathrm{CE}$, de Martin AS. Investigation of the efficacy of passive ultrasonic irrigation versus irrigation with reciprocating activation: an environmental scanning electron microscopic study. J Endod 2016;42(4):659-663

15 Brito PRR, Souza LC, Machado de Oliveira JC, et al. Comparison of the effectiveness of three irrigation techniques in reducing intracanalEnterococcus faecalispopulations: an in vitro study. J Endod 2009;35(10):1422-1427

16 Siqueira JF Jr, Rôças IN, Santos SR, Lima KC, Magalhães FA, de Uzeda M. Efficacy of instrumentation techniques and irrigation regimens in reducing the bacterial population within root canals. J Endod 2002;28(3):181-184

17 Matos Neto M, Santos SS, Leão MV, Habitante SM, Rodrigues JR, Jorge AO. Effectiveness of three instrumentation systems to removeEnterococcus faecalisfrom root canals. Int Endod J 2012;45(5):435-438

18 Gorduysus M, Nagas E, Torun OY, Gorduysus O. A comparison of three rotary systems and hand instrumentation technique for the elimination of Enterococcus faecalis from the root canal. Aust Endod J 2011;37(3):128-133

19 Aydin C, Tunca YM, Senses Z, Baysallar M, Kayaoglu G, Ørstavik D. Bacterial reduction by extensive versus conservative root canal instrumentation in vitro. Acta Odontol Scand 2007;65(3):167-170

20 Paragliola R, Franco V, Fabiani C, et al. Final rinse optimization: influence of different agitation protocols. J Endod 2010;36(2):282-285

21 Castelo-Baz P, Martín-Biedma B, Cantatore G, et al. In vitro comparison of passive and continuous ultrasonic irrigation in simulated lateral canals of extracted teeth. J Endod 2012;38(5):688-691

22 Molander A, Reit C, Dahlén G, Kvist T. Microbiological status of root-filled teeth with apical periodontitis. Int Endod J 1998;31(1):1-7

23 Siqueira JF Jr, Rôças IN. Microbiology and treatment of acute apical abscesses. Clin Microbiol Rev 2013;26(2):255-273

24 White JM, Goodis HE, Marshall SJ, Marshall GW. Sterilization of teeth by gamma radiation. J Dent Res 1994;73(9):1560-1567

25 Love RM. Invasion of dentinal tubules by root canal bacteria. Endod Topics 2004;9:52-65

26 Ran S, Wang J, Jiang W, Zhu C, Liang J. Assessment of dentinal tubule invasion capacity of Enterococcus faecalis under stress conditions ex vivo. Int Endod J 2015;48(4):362-372

27 Tennert C, Fuhrmann M, Wittmer A, et al. New bacterial composition in primary and persistent/secondary endodontic infections with respect to clinical and radiographic findings. J Endod 2014;40(5):670-677

28 Jensen SA, Walker TL, Hutter JW, Nicoll BK. Comparison of the cleaning efficacy of passive sonic activation and passive ultrasonic activation after hand instrumentation in molar root canals. J Endod 1999;25(11):735-738

29 Duque JA, Duarte MA, Canali LC, et al. Comparative effectiveness of new mechanical irrigant agitating devices for debris removal from the canal and isthmus of mesial roots of mandibular molars. J Endod 2017;43(2):326-331

30 Simezo AP, da Silveira Bueno CE, Cunha RS, et al. Comparative analysis of dentinal erosion after passive ultrasonic irrigation versus irrigation with reciprocating activation: an environmental scanning electron study. J Endod 2017;43(1):141-146

31 Huffaker SK, Safavi K, Spangberg LS, Kaufman B. Influence of a passive sonic irrigation system on the elimination of bacteria from root canal systems: a clinical study. J Endod 2010;36(8):1315-1318

32 van der Sluis LW, Vogels MP, Verhaagen B, Macedo R, Wesselink PR. Study on the influence of refreshment/activation cycles and irrigants on mechanical cleaning efficiency during ultrasonic activation of the irrigant. J Endod 2010;36(4):737-740

33 Andrade CV Jr., Batista MR, Alves MM, Alves F, Silva JN. Efficacy of a new activation device in irrigant penetration into simulated lateral canals. Euro Endod J 2016;3:1-5 